Check for updates

Cite this: Chem. Commun., 2018, 54,10160

Received 28th June 2018,

Accepted 14th August 2018

DOI: $10.1039 / \mathrm{c} 8 \mathrm{cc} 05178 \mathrm{j}$

rsc.li/chemcomm

\section{Reductive cyclisations of amidines involving aminal radicals $\dagger$}

\author{
Huan-Ming Huang, (D) Ralph W. Adams (D) and David J. Procter (D) *
}

\begin{abstract}
Amidines bearing simple alkenes undergo aminal radical cyclisation upon treatment with $\mathrm{Sml}_{2}$. The mild, reductive electron transfer process delivers medicinally-relevant, polycyclic quinazolinone derivatives in good to excellent yield and typically with complete diastereocontrol.
\end{abstract}

Nitrogen-containing heterocycles are ubiquitous components in the molecular architectures of natural products, materials and drug candidates. ${ }^{1}$ As a feature in biologically active alkaloids, ${ }^{2}$ the quinazolinone ring system is a significant member of the family and its presence in nature has inspired the search for synthetic quinazolinones with medicinal potential (Scheme 1A). ${ }^{3}$ Although various approaches to these polycyclic scaffolds have been described, ${ }^{4}$ expedient, stereoselective synthetic strategies to quinazolinones that operate under mild conditions on simple, readily accessible substrates, are of high value.

Radical cyclisations have emerged as an important tool for the efficient generation of complex polycyclic products. ${ }^{5}$ However, few radical cyclisation strategies have been developed for the synthesis of quinazolinone analogues. ${ }^{6}$ Of these, Malacria, Courillon and Fensterbank have described an elegant radical cyclisation approach using tributyltin hydride and applied the method to a synthesis of Luotonin A. ${ }^{6 a-f}$ Weaver and Bowman have also reported a radical cyclisation approach to quinazolinones using tributyltin hydride. ${ }^{6 g}$ Recently, Chiba reported an elegant oxidative radical rearrangement that constructs quinazolinones. ${ }^{6 h, i}$ Finally, quinazolinone scaffolds have been accessed using radical processes involving $\mathrm{Ag}(\mathrm{I})^{6 j}$ and $\mathrm{Cu}(\mathrm{I}),{ }^{6 k}$ visible-light photoredox catalysis, ${ }^{6 l}$ and DTBP in a metal-free process. ${ }^{6 m}$ Despite these reports, ${ }^{6}$ there remains a need for a straightforward method that constructs polycyclic quinazolinones under mild conditions.

School of Chemistry, Oxford Road, University of Manchester, Manchester, M13 9PL, UK. E-mail: david.j.procter@manchester.ac.uk

$\dagger$ Electronic supplementary information (ESI) available: General experimental procedures, characterization details, ${ }^{1} \mathrm{H}$ and ${ }^{13} \mathrm{C}$ NMR spectra of compounds, X-ray crystallographic data for $2 \mathbf{a}, 2 \mathrm{~g}$ and $2 \mathbf{t}$, nOe study and analysis of coupling constants for 2u. CCDC 1846530-1846532. For ESI and crystallographic data in CIF or other electronic format see DOI: $10.1039 / \mathrm{c} 8 \mathrm{cc} 05178 \mathrm{j}$

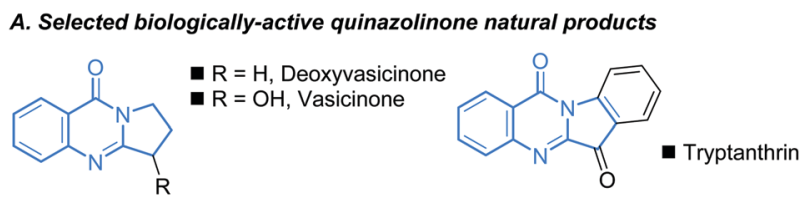

B. Cyclisations of aminal radicals formed from amidines by SET

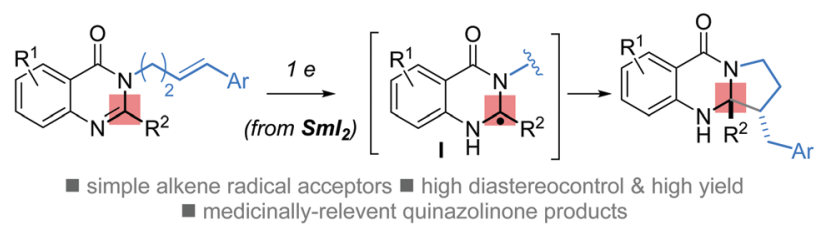

Scheme 1 (A) Selected biologically-active quinazolinone natural products (B) this work: the cyclisation of aminal radicals, formed from amidines by SET, provides efficient access to quinazolinones.

We recently reported the first radical reduction, cyclisations and cyclisation cascades involving radical anions generated from urea-type carbonyls by single electron transfer (SET). ${ }^{7}$ During the study, we found that the aminal radical anion intermediates could be generated and trapped by tethered alkenes to form heterocyclic products. ${ }^{7 a}$ Related aminal radicals were formed and trapped, in an intermolecular sense, by Beaudry in his highly effective cross-coupling of amidines with electrondeficient alkenes. ${ }^{8}$ Both processes are mediated by the reductive SET reagent, samarium iodide ( $\mathrm{SmI}_{2}$, Kagan's reagent). ${ }^{9}$ This highly versatile, commercially available or readily prepared reagent often proves to be the only viable mediator of challenging radical cyclisations and cyclisation cascades designed to deliver high value products not easily accessible by alternative means. ${ }^{10}$ Crucially, in Beaudry's study, only two intramolecular examples of amidinealkene coupling were described and in all examples, both interand intramolecular, alkenes bore strongly electron-withdrawing groups. ${ }^{8 a}$ We recognised that the intramolecular $\mathrm{SmI}_{2}$-mediated coupling of amidines with simple unactivated alkene radical acceptors could provide expedient access to important quinazolinones. Herein, we describe the first general study of aminal radical cyclisations triggered by SET reduction of amidines using 
Table 1 Optimisation of amidine-alkene radical cyclisations ${ }^{a}$

\begin{tabular}{|c|c|c|c|c|c|}
\hline \multirow[b]{2}{*}{ Entry } & \multirow[b]{2}{*}{$\mathrm{SmI}_{2}$ (equiv.) } & \multirow[b]{2}{*}{$\mathrm{NH}_{4} \mathrm{Cl}$ (equiv.) } & \multirow[b]{2}{*}{$\mathrm{H}_{2} \mathrm{O}$ (equiv.) } & \multicolumn{2}{|c|}{ Yield $^{b}[\%]$} \\
\hline & & & & $1 \mathrm{a}$ & $2 a$ \\
\hline 1 & 3 & - & - & - & 50 \\
\hline 2 & 3 & 3 & - & - & 57 \\
\hline 3 & 3 & - & 100 & - & 61 \\
\hline $4^{c}$ & 3 & - & - & - & 60 \\
\hline 5 & 3 & - & 3 & - & 55 \\
\hline 6 & 3 & - & 20 & - & 58 \\
\hline $7^{d}$ & 3 & - & 100 & - & 26 \\
\hline $8^{e}$ & 3 & 3 & - & - & $84(81)^{j}$ \\
\hline
\end{tabular}

${ }^{a}$ Reaction conditions: 1a $\left(0.1 \mathrm{mmol}\right.$, in THF) under $\mathrm{N}_{2}$, was added proton source followed by $\mathrm{SmI}_{2}(0.1 \mathrm{M}$ in THF). The reaction was quenched after 2 h. ${ }^{b}$ Yield was determined by ${ }^{1} \mathrm{H}$ NMR spectroscopy using 2,3,5,6-tetrachloronitrobenzene as internal standard. ${ }^{c} 10$ equiv. $t$-BuOH was added. ${ }^{d} 100$ equiv. $\mathrm{LiBr}$ was added. ${ }^{e}$ The $\mathrm{SmI}_{2}$ solution was added over $1 \mathrm{~h}$ by syringe pump. ${ }^{f}$ Isolated yield.

$\mathrm{SmI}_{2}$ (Scheme 1B). The radical cyclisations deliver quinazolinones in good yield and typically with complete diastereocontrol.

We began our studies by optimising the cyclisation of 1a; efficiently synthesised in one step from commercial 4-hydroxyquinazoline. Pleasingly, the desired cyclisation product 2a was obtained in $50 \%$ yield upon treatment with $\mathrm{SmI}_{2}$ (Table 1, entry 1 ). The fact that $\mathrm{SmI}_{2}$, in the absence of additives that increase the reducing power of the reagent, can reduce 1a highlights the reactive nature of the $N$-acyl amidine functional group relative to, for example, amides, ${ }^{11 a}$ acids, ${ }^{11 b}$ esters, ${ }^{11 c}$ and nitriles. ${ }^{11 d}$ Drawing on the observations of Beaudry, $\mathrm{NH}_{4} \mathrm{Cl}$ proved to be an effective proton source in the reductive coupling, and its use gave $2 \mathrm{a}$ in $57 \%$ yield (entry 2). Using the more established proton sources, $\mathrm{H}_{2} \mathrm{O}$ and $t-\mathrm{BuOH}$, resulted in the formation of $2 \mathbf{a}$ in $61 \%$ and $60 \%$ yield, respectively (entries 3 and 4 ). When the amount of $\mathrm{H}_{2} \mathrm{O}$ was reduced, the yield of $3 \mathbf{a}$ did not improve (entries 5 and 6). The use of $\mathrm{LiBr}$ as an additive in combination with $\mathrm{H}_{2} \mathrm{O}^{12}$ gave $2 \mathrm{a}$ in a lower $26 \%$ yield (entry 7 ). The key to further improvement in the yield of $2 \mathrm{a}$ proved to lie in the rate of addition of the SET reagent; slow addition of $\mathrm{SmI}_{2}$ gave $2 \mathrm{a}$ in $81 \%$ isolated yield (entry 8). It is likely that slow addition prevents the over-reduction of aminal radical I that would compete with radical cyclisation. The combination of $\mathrm{SmI}_{2}$ and $\mathrm{H}_{2} \mathrm{O}$ was clearly too reducing for the amidine substrate (even with slow addition of $\mathrm{SmI}_{2}$ ) and thus Beaudry's $\mathrm{NH}_{4} \mathrm{Cl}$ additive was used in further studies.

Using the optimised conditions, we have explored the generality of the amidine-alkene radical cyclisation (Scheme 2). In all cases, the desired quinazolinone products of cyclisation were obtained with complete diastereocontrol ( $>95: 5 \mathrm{dr}$ ) and in good to excellent yield. Various functional groups on the alkenyl aryl ring were found to be compatible with the reductive conditions, including methoxy (2c, 2d), bromo (2e), chloro (2h), trifluoromethyl (2f), and acetal (2g). Furthermore, the presence of medicinally-relevant heteroaromatic rings including indole (2k), benzothienyl (2l and $2 \mathbf{m}$ ), and
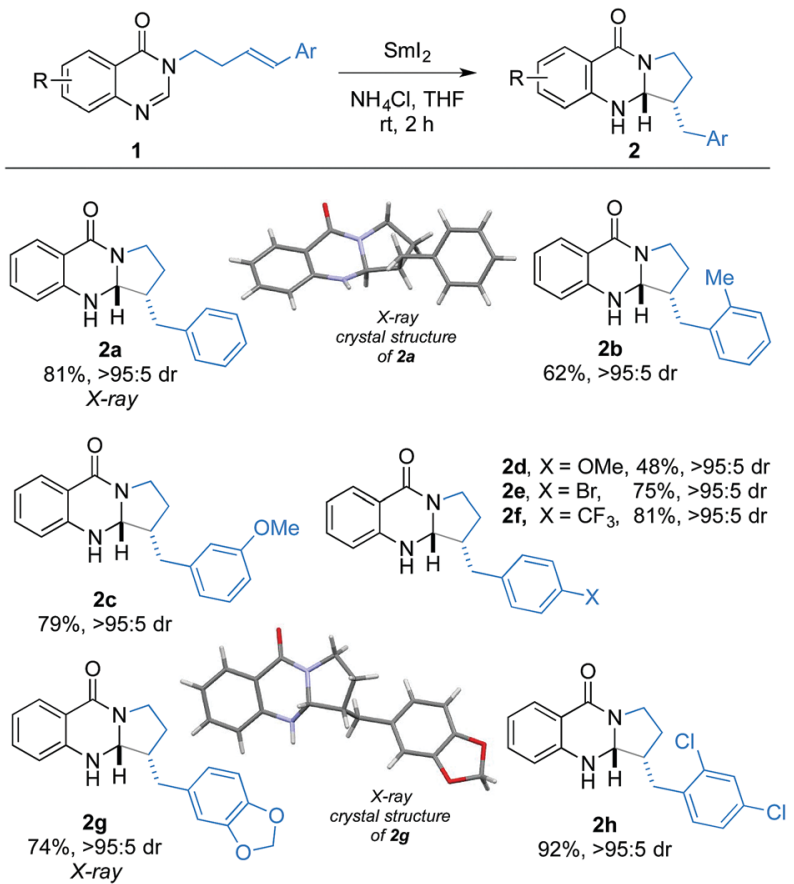<smiles>COC(=O)[C@@H](Cc1ccccc1)C12CCN(C1)C(=O)C(=O)c1ccccc1N2</smiles><smiles>O=C1c2ccccc2NC2(C(c3ccccc3)c3ccccc3)C(c3ccccc3)CCN12</smiles>
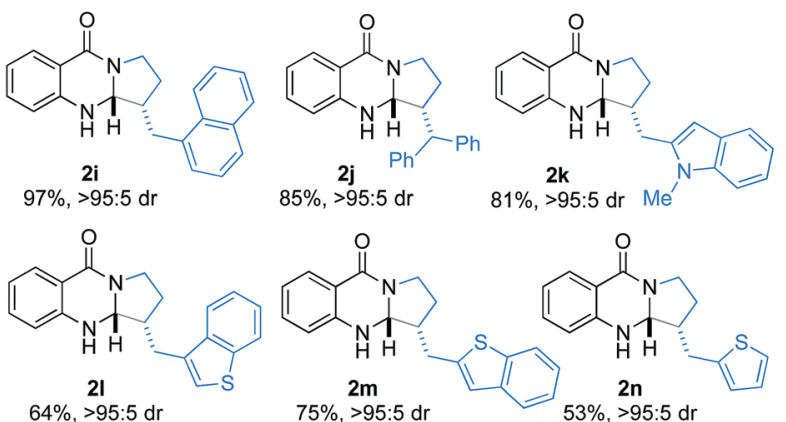

$85 \%,>95: 5 d r$ $81 \%,>95: 5 \mathrm{dr} M \mathrm{Me}^{\prime}$
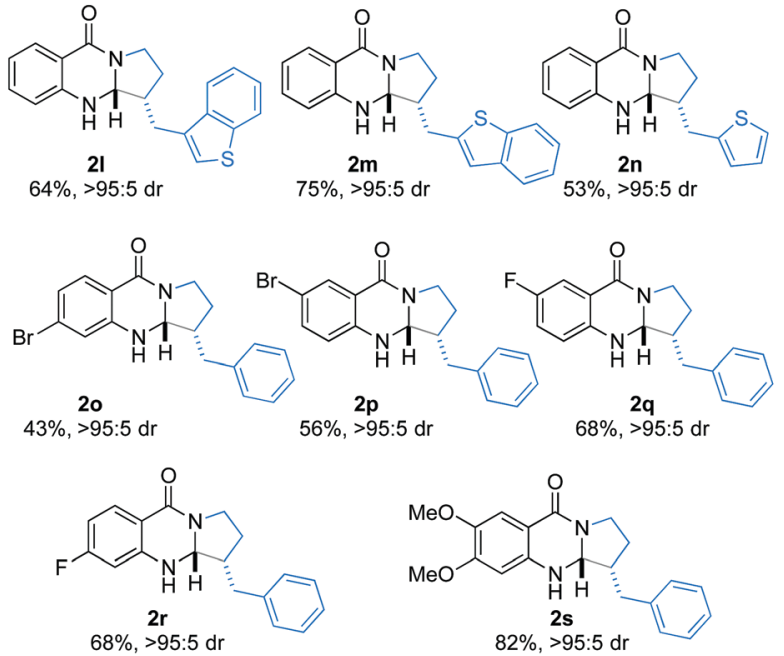

Scheme 2 Scope of the amidine radical cyclisation. Reaction conditions: 1a $(0.1 \mathrm{mmol})$ and $\mathrm{NH}_{4} \mathrm{Cl}(0.3 \mathrm{mmol})$ in THF $(2 \mathrm{~mL})$ under $\mathrm{N}_{2}$, was added $\mathrm{Sml}_{2}$ (0.1 $\mathrm{M}$ in THF, 3 equiv.) over $1 \mathrm{~h}$ using a syringe pump. The reaction was quenched after another $1 \mathrm{~h}$. Isolated yield.

thienyl (2n) did not impede radical cyclisation. Finally, various functional groups on the benzenoid ring of the 4-quinazolinone motif, including bromo (2o and $2 \mathbf{p}$ ), fluoro (2q and $2 \mathbf{r}$ ) and methoxy (2s), were also tolerated in the radical cyclisation. The relative configuration of the quinazolinone products was assigned after X-ray crystallographic analysis of $2 \mathbf{a}$ and $2 \mathbf{g} .{ }^{13}$

The radical cyclisation could be carried out on gram-scale with no loss of efficiency: Using the optimised conditions, 1a 


\section{A. Gram-scale Experiment}

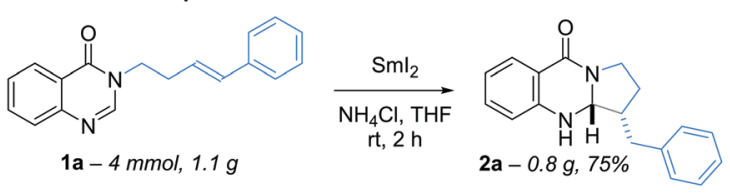

B. Construction of Quaternary Carbon Stereocenters

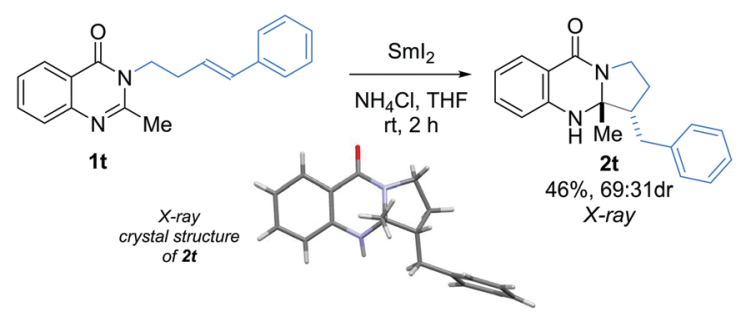

C. Extension to 6-exo-trig cyclisation<smiles>C=[N+]1C=C(CCC/C=C/c2cccc(N)c2)C(=O)c2ccccc21</smiles>

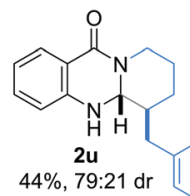

D. Deuterium Labeling Experiment

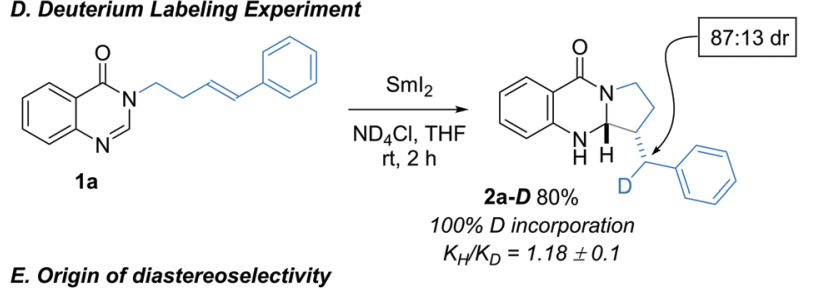

E. Origin of diastereoselectivity

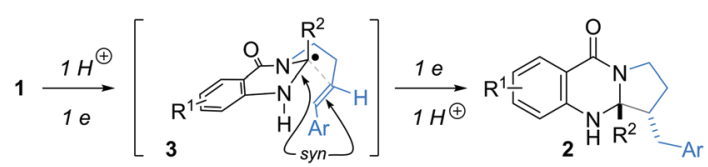

Scheme 3 (A) A gram-scale experiment; (B) construction of quaternary carbon stereocenters; (C) extension to 6-exo-trig cyclisation; (D) deuterium labelling experiment; (E) origin of diastereoselectivity.

( $4.0 \mathrm{mmol}, 1.1 \mathrm{~g})$ was converted to $2 \mathrm{a}(3.0 \mathrm{mmol}, 0.83 \mathrm{~g})$ in $75 \%$ yield (Scheme 3A). In addition, radical cyclisation of 2-methyl quinazolin-4-one $\mathbf{1 t}$ gave $\mathbf{2 t}$ containing a quaternary carbon center in $46 \%$ isolated yield as $2: 1$ mixture of diastereoisomers (Scheme 3B). The structure of the major diastereoisomer of $\mathbf{2 t}$ was confirmed by X-ray crystallographic analysis. ${ }^{13}$ Substrate $\mathbf{1 u}$ underwent a challenging 6-exo-trig cyclisation to give $2 \mathbf{u}$ in $44 \%$ isolated yield with moderate diastereocontrol. In this case, the anti diastereoisomeric product predominated, as determined by NOE and also supported by the comparison of measured and calculated coupling constants (Scheme 3C). ${ }^{14}$ A deuterium labeling experiment was also performed using $\mathrm{SmI}_{2}-\mathrm{ND}_{4} \mathrm{Cl}$. As expected, the labelled cyclisation product $\mathbf{2 a}-\boldsymbol{D}$ was obtained, thus confirming that the cyclisation is terminated by protonation of a benzylic organosamarium (100\% D incorporation, 83:17 dr at the labelled benzylic position). ${ }^{15}$ The KIE measured for this reductive cyclisation suggests that proton transfer is not involved in the rate-determining step (Scheme 3D). Finally, a likely transition structure for the 5-exo-trig radical cyclisation that explains the origin of the syn-diastereoselectivity is shown in Scheme 3E. In contrast, to the cyclisations of ketyl radical anions that often proceed to give anti-products, ${ }^{16}$ the cyclisation of neutral aminal radical $\mathbf{I}$, formed by protonation of a radical anion after SET or by protonation of the amidine prior to SET, favours cyclisation via syn-transition structure 3.

In summary, reductive amidine-alkene radical cyclisations, involving the intramolecular addition of aminal radicals to simple alkenes, deliver polycyclic quinazolinones. The radical process is mediated by single electron transfer from commercially available $\mathrm{SmI}_{2}$, operates under mild conditions on readily-available substrates, proceeds with complete diastereocontrol, and delivers a range of medicinally-relevant, quinazolinone derivatives in good to excellent yield.

We thank the EPSRC (EPSRC Established Career Fellowship to D. J. P.; EP/M005062/1), EPSRC Core Capability Grant (EP/K039547/1), the Leverhulme Trust (Research Fellowship to D. J. P.; RF-2013-286), and the University of Manchester (President's Scholarship to H. H.) for funding.

\section{Conflicts of interest}

There are no conflicts to declare.

\section{Notes and references}

1 For reviews on nitrogen-containing heterocycles, see: (a) J. P. Michael, Nat. Prod. Rep., 2002, 19, 719; (b) P. A. Evans and B. Holmes, Tetrahedron, 1991, 47, 9131; (c) Y. Yamamoto, Chem. Soc. Rev., 2014, 43, 1575; (d) B. H. Lipshutz, Chem. Rev., 1986, 86, 795.

2 Selected reviews, see: (a) S. B. Mhaske and N. P. Argade, Tetrahedron, 2006, 62, 9787; (b) D. J. Connolly, D. Cusack, T. P. O'Sullivan and P. J. Guiry, Tetrahedron, 2005, 61, 10153; (c) I. Khan, A. Ibrar, N. Abbas and A. Saeed, Eur. J. Med. Chem., 2014, 76, 193; (d) I. Khan, A. Ibrar, W. Ahmed and A. Saeed, Eur. J. Med. Chem., 2015, 90, 124; (e) L. He, H. Li, J. Chen and X.-F. Wu, $R S C A d v$., 2014, 4, 12065; $(f)$ U. A. Kshirsagar, Org. Biomol. Chem., 2015, 13, 9336; $(g)$ P. C. Sharma, G. Kaur, R. Pahwa, A. Sharma and H. Rajak, Curr. Med. Chem., 2011, 18, 4786; (h) R. Rohokale and U. A. Kshirsagar, Synthesis, 2016, 1253.

3 (a) Z.-Z. Ma, Y. Hano, T. Nomura and Y.-J. Chen, Heterocycles, 1997, 46, 541; (b) A. Astulla, K. Zaima, Y. Matsuno, Y. Hirasawa, W. Ekasari, A. Widyawaruyanti, N. C. Zaini and H. Morita, J. Nat. Med., 2008, 62, 470-472; (c) A. Al-Shamma, S. Drake, D. L. Flynn, L. A. Mitscher, Y. H. Park, G. S. R. Rao, A. Simpson, J. K. Swayze, T. Veysoglu and S. T.-S. Wu, J. Nat. Prod., 1981, 44, 745-747.

4 Selected elegant examples of total synthesis of related natural produts, see: (a) S. B. Mhaske and N. P. Argade, J. Org. Chem., 2001, 66, 9038; (b) J.-F. Liu, P. Ye, K. Sprague, K. Sargent, D. Yohannes, C. M. Baldino, C. J. Wilson and S.-C. Ng, Org. Lett., 2005, 7, 3363; (c) S. P. Chavan and R. Sivappa, Tetrahedron Lett., 2004, 45, 997.

5 Selected reviews and book, see: $(a)$ M. P. Plesniak, H.-M. Huang and D. J. Procter, Nat. Rev. Chem., 2017, 1, 0077; (b) J. Xuan and A. Studer, Chem. Soc. Rev., 2017, 46, 4329; (c) B. M. Loertscher and S. L. Castle, in Comprehensive Organic Synthesis II, Elsevier, 2014, pp. 742-809; (d) K. C. Majumdar, P. K. Basu and S. K. Chattopadhyay, Tetrahedron, 2007, 63, 793; (e) A. J. Clark, Chem. Soc. Rev., 2002, 31, 1; $(f)$ A. G. Fallis and I. M. Brinza, Tetrahedron, 1997, 53, 17543; $(g)$ B. B. Snider, Chem. Rev., 1996, 96, 339; (h) S. Kim, Pure Appl. Chem., 1996, 68, 623.

6 Selected examples of the synthesis of quinazolinone scaffolds invloving radical cyclisation, see (a) A. Servais, M. Azzouz, D. Lopes, C. Courillon and M. Malacria, Angew. Chem., Int. Ed., 2007, 46, 576; (b) A. Beaume, C. Courillon, E. Derat and M. Malacria, Chem. - Eur. J., 2008, 14, 1238; (c) M.-H. Larraufie, C. Ollivier, L. Fensterbank, M. Malacria and E. Lacôte, Angew. Chem., Int. Ed., 2010, 49, 2178; (d) M.-H. Larraufie, C. Courillon, C. Ollivier, E. Lacôte, M. Malacria and L. Fensterbank, J. Am. Chem. Soc., 2010, 132, 4381; (e) M.-H. Larraufie, G. Maestri, M. Malacria, C. Ollivier, L. Fensterbank and E. Lacôte, Synthesis, 2012, 
1279; $(f)$ M.-H. Larraufie, M. Malacria, C. Courillon, C. Ollivier, L. Fensterbank and E. Lacôte, Tetrahedron, 2013, 69, 7699; $(g)$ W. R. Bowman, M. R. J. Elsegood, T. Stein and G. W. Weaver, Org. Biomol. Chem., 2007, 5, 103; (h) Y. F. Wang, F. L. Zhang and S. Chiba, Org. Lett., 2013, 15, 2842; (i) F.-L. Zhang, Y.-F. Wang and S. Chiba, Org. Biomol. Chem., 2013, 11, 6003; $(j)$ J. Zheng, Y. Zhang, D. Wang and S. Cui, Org. Lett., 2016, 18, 1768; ( $k$ ) J. Zheng, Z. Deng, Y. Zhang and S. Cui, Adv. Synth. Catal., 2016, 358, 746; (l) P. Qian, Y. Deng, H. Mei, J. Han, J. Zhou and Y. Pan, Org. Lett., 2017, 19, 4798; $(m)$ X.-K. Liu, P. Qian, Y. Wang and Y. Pan, Org. Chem. Front., 2017, 4, 2370; (n) Q. Li, Y. Huang, T. Chen, Y. Zhou, Q. Xu, S. F. Yin and L. B. Han, Org. Lett., 2014, 16, 3672; (o) Y. Bao, Y. Yan, K. Xu, J. Su, Z. Zha and Z. Wang, J. Org. Chem., 2015, 80, 4736; (p) T. Yang, W. Wang, D. Wei, T. Zhang, B. Han and W. Yu, Org. Chem. Front., 2017, 4, 421; (q) A. V. A. Gholap, S. Maity, C. Schulzke, D. Maiti and A. R. Kapdi, Org. Biomol. Chem., 2017, 15, 7140; (r) Á. Gutiérrez-Bonet, C. Remeur, J. K. Matsui and G. A. Molander, J. Am. Chem. Soc., 2017, 139, 12251; (s) P. S. Mahajan and S. B. Mhaske, Org. Lett., 2018, 20, 2092.

7 (a) H.-M. Huang, J. J. W. McDouall and D. J. Procter, Angew. Chem., Int. Ed., 2018, 57, 4995; (b) H.-M. Huang and D. J. Procter, Eur. J. Org. Chem., 2018, DOI: 10.1002/ejoc.201800794.

8 (a) D. A. Schiedler, Y. Lu and C. M. Beaudry, Org. Lett., 2014, 16, 1160; (b) D. A. Schiedler, J. K. Vellucci, Y. Lu and C. M. Beaudry, Tetrahedron, 2015, 71, 1448. Aminal radicals could also be generated under $\mathrm{Bu}_{3} \mathrm{SnH}$ or $(\mathrm{TMS})_{3} \mathrm{SiH}$ conditions, and have been applied in the carbon-carbon bond forming reaction, see: $(c)$ D. A. Schiedler, J. K. Vellucci and C. M. Beaudry, Org. Lett., 2012, 14, 6092.

9 Selected leading reviews on $\mathrm{SmI}_{2}$-mediated radical cyclisations and cyclisation cascades, see: (a) S. Shi and M. Szostak, Molecules, 2017, 22, 2018; (b) X. Just-Baringo and D. J. Procter, Acc. Chem. Res., 2015, 48, 1263; (c) M. Szostak, N. J. Fazakerley, D. Parmar and D. J. Procter, Chem. Rev., 2014, 114, 5959; (d) C. Beemelmanns and H.-U. Reissig, Chem. Soc. Rev., 2011, 40, 2199; (e) C. Beemelmanns and H.-U. Reissig, Pure Appl. Chem., 2011, 83, 507; $(f)$ K. C. Nicolaou, S. P. Ellery and J. S. Chen, Angew. Chem., Int. Ed., 2009, 48, 7140; $(g)$ D. J. Procter, R. A. Flowers, II and T. Skrydstrup, Organic Synthesis using Samarium Diiodide: A Practical Guide, RSC Publishing, Cambridge, 2009; (h) R. Flowers, II, Synlett, 2008, 1427; ( $i$ ) D. J. Edmonds, D. Johnston and D. J. Procter, Chem. Rev., 2004, 104, 3371; (j) G. A. Molander and C. R. Harris, Chem. Rev., 1996, 96, 307; (k) G. A. Molander, Chem. Rev., 1992, 92, 29.
10 For selected recent examples of Sm(II)-mediated radical cyclisations, see: (a) C. Morrill, C. Jensen, X. Just-Baringo, G. Grogan, N. J. Turner and D. J. Procter, Angew. Chem., Int. Ed., 2018, 57, 3692; (b) N. Kern, M. P. Plesniak, J. J. W. McDouall and D. J. Procter, Nat. Chem., 2017, 9, 1198; (c) H.-M. Huang and D. J. Procter, Angew. Chem., Int. Ed., 2017, 56, 14262; (d) H.-M. Huang and D. J. Procter, J. Am. Chem. Soc., 2017, 139, 1661; (e) H.-M. Huang, P. Bonilla and D. J. Procter, Org. Biomol. Chem., 2017, 15, 4159; $(f)$ H.-M. Huang and D. J. Procter, J. Am. Chem. Soc., 2016, 138, 7770; $(g)$ S. Shi, R. Lalancette, R. Szostak and M. Szostak, Chem. - Eur. J., 2016, 22, 11949; (h) S. Shi and M. Szostak, Org. Lett., 2015, 17, 5144; (i) Z. Li, M. Nakashige and W. J. Chain, J. Am. Chem. Soc., 2011, 133, 6553; (j) J. Y. Cha, J. T. S. Yeoman and S. E. Reisman, J. Am. Chem. Soc., 2011, 133, 14964; ( $k$ ) C. Beemelmanns and H.-U. Reissig, Angew. Chem., Int. Ed., 2010, 49, 8021; (l) M. D. Helm, M. Da Silva, D. Sucunza, T. J. K. Findley and D. J. Procter, Angew. Chem., Int. $E d$., 2009, 48, 9315; $(m)$ S. E. Reisman, J. M. Ready, M. M. Weiss, A. Hasuoka, M. Hirata, K. Tamaki, T. V. Ovaska, C. J. Smith and J. L. Wood, J. Am. Chem. Soc., 2008, 130, 2087.

11 (a) M. Szostak, M. Spain, A. J. Eberhart and D. J. Procter, J. Am. Chem. Soc., 2014, 136, 2268; (b) M. Szostak, M. Spain and D. J. Procter, Org. Lett., 2012, 14, 840; (c) M. Szostak, M. Spain and D. J. Procter, Chem. Commun., 2011, 47, 10254; (d) M. Szostak, B. Sautier, M. Spain and D. J. Procter, Org. Lett., 2014, 16, 1092.

$12 \mathrm{SmI}_{2}-\mathrm{H}_{2} \mathrm{O}-\mathrm{LiBr}$ has recently been used to promote radical cyclisations and cyclisation cascades. For example, see: $(a)$ C. N. Rao, D. Lentz and H.-U. Reissig, Angew. Chem., Int. Ed., 2015, 54, 2750; (b) C. N. Rao, C. Bentz and H.-U. Reissig, Chem. - Eur. J., 2015, 21, 15951. And ref. $10 e-g$.

13 See ESI $\dagger$ for X-ray structures and CCDC numbers (CCDC 1846530 for 2a, 1846531 for $2 \mathrm{~g}$ and 1846532 for $2 \mathrm{t}$ ).

$14 \mathrm{See} \mathrm{ESI} \dagger$ for NOE experiments and a comparison of measured and calculated $\mathrm{J}$ values.

15 X. Just-Baringo, J. Clark, M. J. Gutmann and D. J. Procter, Angew. Chem., Int. Ed., 2016, 55, 12499.

16 For a review, see: (a) A. L. J. Beckwith, Tetrahedron, 1981, 37, 3073. For selected examples, see: (b) G. A. Molander and C. Kenny, J. Am. Chem. Soc., 1989, 111, 8236; (c) G. A. Molander and J. A. McKie, J. Org. Chem., 1995, 60, 872; (d) D. Johnston, C. M. McCusker and D. J. Procter, Tetrahedron Lett., 1999, 40, 4913. 